\title{
A Panel Threshold Model of Tourism Specialization and Economic Development*
}

\author{
Chia-Lin Chang \\ Department of Applied Economics \\ National Chung Hsing University \\ Taichung, Taiwan \\ Thanchanok Khamkaew \\ Faculty of Economics \\ Chiang Mai University \\ Thailand \\ Michael McAleer \\ Econometric Institute \\ Erasmus School of Economics \\ Erasmus University Rotterdam \\ and \\ Tinbergen Institute \\ The Netherlands \\ and \\ Center for International Research on the Japanese Economy (CIRJE) \\ Faculty of Economics \\ University of Tokyo
}

EI2009-40

October 2009

* For financial support, the first author is grateful to the National Science Council, Taiwan, and the third author wishes to acknowledge the Australian Research Council and National Science Council, Taiwan. 


\begin{abstract}
The significant impact of international tourism in stimulating economic growth is especially important from a policy perspective. For this reason, the relationship between international tourism and economic growth would seem to be an interesting empirical issue. In particular, if there is a causal link between international tourism demand and economic growth, then appropriate policy implications may be developed. The purpose of this paper is to investigate whether tourism specialization is important for economic development in East Asia and the Pacific, Europe and Central Asia, Latin America and the Caribbean, the Middle East and North Africa, North America, South Asia, and Sub-Saharan Africa, over the period 1991-2008. The impact of the degree of tourism specialization, which is incorporated as a threshold variable, on economic growth is examined for a wide range of countries at different stages of economic development. The empirical results from threshold estimation identify two endogenous cut-off points, namely $14.97 \%$ and $17.50 \%$. This indicates that the entire sample should be divided into three regimes. The results from panel threshold regression show that there exists a positive and significant relationship between economic growth and tourism in two regimes, the regime with the degree of tourism specialization lower than $14.97 \%$ (regime 1) and the regime with the degree of tourism specialization between $14.97 \%$ and $17.50 \%$ (regime 2). However, the magnitudes of the impact of tourism on economic growth in those two regimes are not the same, with the higher impact being found in regime 2. An insignificant relationship between economic growth and tourism is found in regime 3, in which the degree of tourism specialization is greater than $17.50 \%$. The empirical results suggest that tourism growth does not always lead to economic growth.
\end{abstract}

Keywords: International tourism, economic development, tourism specialization, threshold variable, panel data.

JEL Classifications: C33, L83, O10, O40, O57. 


\section{Introduction}

Tourism has grown enormously as a result of the globalization process. Tourism is described as a movement in the direction of increasing world economic integration through the reduction of natural and human barriers to exchange and increase international flows of capital and labour. Improvements in transportation include the introduction of low-cost air carriers, the emergence of new markets such as China and India, and diversification into new market niches, such as cultural tourism and ecotourism, are considered as key factors supporting tourism.

According to the UNWTO World Tourism Barometer publication in 2008 (2009), international tourist arrivals figures reached 924 million. This was an increase of 16 million from 2007 , thereby representing a growth of $2 \%$ for the full year, but down from $7 \%$ in 2007 (see Figure 1). The demand for tourism slowed significantly throughout the year under the influence of an extremely volatile world economy, such as the financial crisis, price rises in commodities and oil, and a sharp fluctuation in the exchange rate. Based on these events, it seems that the world tourism situation is likely to become more difficult under the current global economic and financial crises.

\section{[Insert Figure 1 here]}

Figure 2 shows that, while Europe ranks first in terms of world arrivals, with the Americas close behind, its share of world total arrivals has decreased. Africa, Latin America and the Caribbean are at the bottom of the list. On the other hand, the Asia-Pacific region has outperformed the rest of the world, with its share of international tourist arrivals having increased rapidly. Some of the strong growth appeared in South-East Asia and East and North-East Asia, especially in Macau and China. Similar evidence is found in the market shares in international tourism receipts (see Figure 3). Europe accounts for about $50 \%$ of world international tourism receipts, followed by Asia and the Pacific region. Once again, Africa, Latin America and the Caribbean remain far behind the other three regions. 


\section{[Insert Figures 2 and 3 here]}

In general, the growth in international tourism arrivals significantly outpaced growth in economic output, as measured by Gross Domestic Product (GDP) (see Figure 4). In years when world economic growth exceeded 4 per cent, the growth in tourism volume has tended to be higher. When GDP growth falls below 2 per cent, tourism growth tends to be even lower. In the period 1975-2000, tourism increased at an average rate of 4.6 per cent per annum (World Tourism Organization, 2008).

\section{[Insert Figure 4 here]}

The roles of travel and tourism activity in the economy are considered in terms of its contribution towards the overall GDP of the region, and its contribution towards overall employment. In many developing regions the travel and tourism sectors have contributed a relatively larger total share to GDP and employment than the world average. The travel and tourism economy GDP, the share to total GDP, the travel and tourism economy employment for all regions in 2009, as well as the future tourism in real growth forecasted by the World Travel and Tourism Council (WTTC) for the next ten years, are given in Table 1.

\section{[Insert Table 1 here]}

In general, some of the impacts of tourism on the economy have not always been regarded as beneficial. Tourism may also be a negative factor related to increased income inequality, damage to the environment, an increase in cultural repercussions, inefficient resource allocation, and other harmful externalities. In order to determine the true impacts of tourism on the economy, the approach to economic evaluation should be more rigorous, and should not ignore the existence of the possible costs related to tourism development. Regardless of the net benefit of tourism, there is a possibility that tourism does not always lead to economic growth. This paper will identify whether tourism leads to economic growth in various economies, classified according to the degree of tourism specialization, and measures the overall impact. 
The main contributions of the paper are as follows. First, no previous studies have rigorously evaluated the relationship between economic growth and tourism in which the roles of domestic and international tourism have been included simultaneously. Most empirical studies have taken the share of international tourism receipts to national GDP to account for influencing economic growth, which leads to the contribution of domestic tourism on the national economy being ignored. In this paper, the travel and tourism (T\&T) economy GDP, which is obtained from the World Travel \& Tourism Council (WTTC) database, is used as a threshold variable in the economic growth-tourism linkage. Second, we examine the nonlinear relationship between economic growth and tourism when using the share of T\&T economy GDP to national GDP as a threshold variable. Finally, two of three regimes are shown to exhibit a positive and significant relationship between economic growth and tourism. For the remaining regime, countries with a degree of tourism specialization over $17.50 \%$, do not exhibit such a significant relationship.

The remainder of the paper is organized as follows. Section 2 presents a literature review. Section 3 describes the data, methodology and empirical framework. The empirical results are analysed in Section 4. Section 5 gives some concluding remarks.

\section{Literature Review}

In the economic growth literature, tourism's contribution to economic development has been well documented, and has long been a subject of interest from a policy perspective. The economic contribution of tourism has usually been considered to be positive to growth (see, for example, Khan et al. (1995), Lee and Kwon (1995), Lim (1997), and Oh (2005)).

The empirical literature on a reciprocal causal relationship between tourism and economic development may be considered in several classifications, depending on the techniques applied. Most historical studies have been based on various time series techniques, such as causality and cointegration, and have relied mainly on individual country or regional analysis. While this allows a deeper conception of the growth process for each country, it also creates difficulties in generalizing the results. Some of the interesting research using this approach include Balaguer 
and Cantavella-Jorda (2002), Dritsakis (2004), Gunduz and Hatemi (2005), Oh (2005), Louca (2006), Kim et al. (2006), and Brida et al. (2008). Even though the possible causal relationship between tourism and economic growth has been empirically analyzed in previous studies, the direction of such relationships has not yet been determined.

Using panel data, there is evidence of an economic growth-tourism nexus in the empirical work of Lee and Chang (2008), Fayissa et al. (2007), and Eugenio-Martin et al. (2004). Nevertheless, there has been little research on the effect on economic growth of the degree of tourism specialization. Sequeria and Campos (2005) used tourism receipts as a percentage of exports and as a percentage of GDP as proxy variables for tourism. A sample of 509 observations for the period 1980 to 1999 was divided into several smaller subsets of data. Their results from pooled OLS, random effects and fixed effects models showed that growth in tourism was associated with economic growth only in African countries. A negative relationship was found between tourism and economic growth in Latin American countries, and in the countries with specialization in tourism. However, they did not find any evidence of a significant relationship between tourism and economic growth in the remainder of the groups.

Brau et al. (2007) investigated the relative economic performance of countries that have specialized in tourism over the period 1980-2003. Tourism specialization and small countries are simply defined as the ratio of international tourism receipts to GDP and as countries with an average population of less than one million during 1980-2003, respectively. They used dummy regression analysis to compare the growth performance of small tourism countries (STCs) as a whole, relative to the performance of a number of significant subsets of countries, namely OECD, Oil, Small, and LDC. They found that tourism could be a growth-enhancing factor, at least for small countries. In other words, small countries are likely to grow faster only when they are highly specialized in tourism. Although the paper considered the heterogeneity among countries in terms of the degree of tourism specialization and country size, the selection of such threshold variables was not based on any selection criteria. It would be preferable to use selection criteria to separate the whole sample into different subsets in which tourism may significantly affect economic growth. 
Po and Huang (2008) use cross section data (1995-2005 yearly averages) for 88 countries to investigate the nonlinear relationship between tourism development and economic growth when the degree of tourism specialization (defined as receipts from international tourism as a percentage of GDP) is used as the threshold variable. The result of the nonlinear threshold model indicated that the data for 88 countries should be divided into three regimes to analyze the tourism-growth nexus. The results of the threshold regression showed that, when the degree of specialization was below 4.05\% (regime 1) or above $4.73 \%$ (regime 3 ), there existed a significantly positive relationship between tourism growth and economic growth. However, when the degree of specialization was between $4.05 \%$ and $4.73 \%$ (regime 2), they were unable to find a significant relationship between tourism and economic growth.

A number of empirical studies, as pointed above, have suggested that there exist thresholds in the effect of tourism on economic growth. However, the endogenous threshold regression technique introduced by Hansen $(1999,2000)$ has not been widely used to identify a nonlinear relationship in the endogenous economic growth model in which the degree of tourism specialization is used as a threshold variable over cross-country panel data sets. Special attention is paid in this paper to establish a new specification of a country's tourism specialization, which is defined as the share of the travel and tourism economy GDP (T\&T economy GDP) to national GDP. T\&T economy GDP measures direct and indirect GDP and employment associated with travel and tourism demand. This is the broadest measure of travel and tourism's contribution to the domestic economy. The T\&T ratio to GDP is used as a criterion for identifying the impact of tourism on economic growth under different conditions.

\section{Data and Methodology}

\subsection{Data}

Subject to the availability of data, 131 countries are used in the sample, as given in Table 2. Annual data for the period 1991 to 2008 are organized in panel data format. The countries in the sample were selected based on data availability. Real GDP per capita (y), inflation $(\pi)$, and the percentage of gross fixed capital formation $(\mathrm{k})$ as a proxy for the capital stock are taken from the 
World Development Indicator (WDI) database. The tourism data are obtained from the World Travel \&Tourism Council (WTTC) website, namely the ratio of real Travel \&Tourism GDP to real national GDP (q), and the ratio of real government expenditure in tourism activities to GDP (g).

\section{[Insert Table 2 here]}

\subsection{Methodology}

The main purpose of this paper is to use a threshold variable to investigate whether the relationship between tourism and economic growth is different in each sample grouped on the basis of certain thresholds. In order to determine the existence of threshold effects between two variables is different from the traditional approach in which the threshold level is determined exogenously. If the threshold level is chosen arbitrarily, or is not determined within an empirical model, it is not possible to derive confidence intervals for the chosen threshold. The robustness of the results from the conventional approach is likely to be sensitive to the level of the threshold. The econometric estimator generated on the basis of exogenous sample splitting may also pose serious inferential problems (for further details, see Hansen $(1999,2000)$ ).

Critical advantages of the endogenous threshold regression technique over the traditional approach are that: (1) it does not require any specified functional form of non-linearity, and the number and location of thresholds are endogenously determined by the data; and (2) asymptotic theory applies, which can be used to construct appropriate confidence intervals. A bootstrap method to assess the statistical significance of the threshold effect, in order to test the null hypothesis of a linear formulation against a threshold alternative, is also available.

For the reasons given above, we follow the panel threshold regression method developed by Hansen (1999) to search for multiple regimes, and to test the threshold effect in the tourism and economic growth relationship. The possibility of endogenous sample separation, rather than imposing a priori an arbitrary classification scheme, and the estimation of a threshold level are allowed in the model. If a relationship exists between these two variables, the threshold model 
can identify the threshold level and test such a relationship over different regimes categorized by the threshold variable.

\section{Panel Threshold Model}

Hansen (1999) developed the econometric techniques appropriate for threshold regression with panel data. Allowing for fixed individual effects, the panel threshold model divides the observations into two or more regimes, depending on whether each observation is above or below the threshold level.

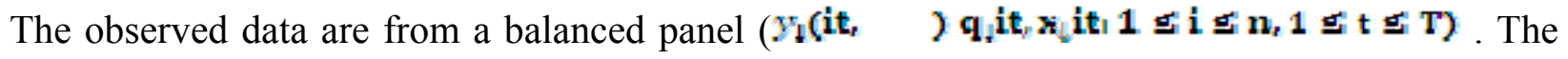
subscript $i$ indexes the individual and $t$ indexes time. The dependent variable $y_{i t}$ is scalar, the threshold variable $\mathbf{q}_{1 \mathrm{t}}$ is scalar, and the regressor $\mathbf{x}_{1 \mathrm{t}}$ is a $k$ vector. The structural equation of interest is

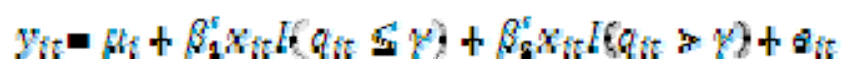

where $I(\cdot)$ is an indicator function. An alternative intuitive way of writing (1) is

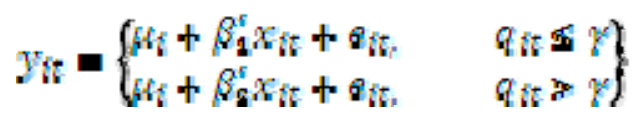

Another compact representation of (1) is to set

$x_{t}(\gamma)=\left\{\begin{array}{l}x_{t t} t\left(q_{n} \leq \gamma\right) \\ x_{t t} t\left(q_{n}>\gamma\right)\end{array}\right\}$

and $\beta=\left(\beta_{1}^{c} \quad \beta_{2}^{c}\right)^{c}$, so that $(1)$ is equivalent to

$$
y_{t t}=\mu_{t}+\beta^{*} x_{t t}(\hat{\gamma})+e_{t t} .
$$


The observations are divided into two regimes, depending on whether the threshold variable $q_{t t}$ is smaller or larger than the threshold $\gamma$. The regimes are distinguished by differing regression slopes, $\beta_{1}$ and $\beta_{2}$. For the identification of $\beta_{1}$ and $\beta_{2}$, it is required that the elements of $x_{2 t}$ are not time-invariant. The threshold variable $\alpha_{i t}$ is not time-invariant. $\mu_{i}$ is the fixed individual effect, and the error $e_{i t}$ is assumed to be independently and identically distributed (iid), with mean zero and finite variance $\sigma^{2}$.

It is easy to see that the point estimates for the slope coefficients $\beta_{\Xi}^{t}$ are dependent on the given threshold value $\gamma$. Since the threshold value is not known and is presumed to be endogenously determined, Hansen (1999) recommends a grid search selection of $\gamma$ that minimizes the sum of squared errors (SSE), denoted $\mathrm{S}_{1}(\gamma)$, which is obtained by least squares estimation of (1):

\section{9. argmtn $S_{1}(2)$.}

Given an estimate of $\gamma$, namely $F_{2} \beta_{1}$ and $\beta_{2}$ can then be estimated, and the slope coefficient

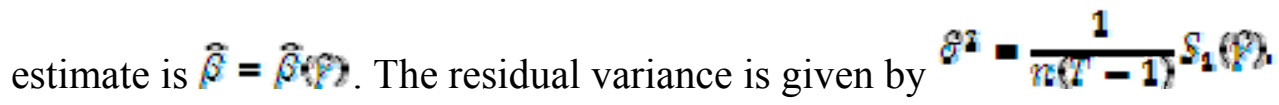

It is not desirable for a threshold estimate, $\vec{F}$ to be selected which sorts too few observations into one regime or another. This possibility can be excluded by restricting the search in (3) to values of $\gamma$ such that a minimal percentage of the observations lies in both regimes. The computation of the least squares estimate of the threshold $\hat{\gamma}$ involves the minimization problem (3).

It is important to determine whether the threshold effect is statistically significant. The null hypothesis of no threshold effects (that is, a linear formulation) against the alternative hypothesis of threshold effects, is given as follows:

$B Q: \beta_{1}=\beta_{2}$

$B_{1}: \ddot{H}_{1} \neq \beta_{2}$ 
Under the null hypothesis, the threshold effect $\gamma$ is not identified, so classical tests such as the Lagrange Multiplier (LM) test do not have the standard distribution. In order to address this problem, a bootstrap procedure is available to simulate the asymptotic distribution of the likelihood ratio test. He showed that a bootstrap procedure attains the first-order asymptotic distribution, so p-values constructed from the bootstrap are asymptotically valid.

After the fixed effect transformation, equation (2) becomes:

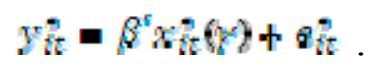

Under the null hypothesis of no threshold effect, the model is given by:

$$
y_{i t}=\mu_{t}+\beta_{1}^{c} x_{t t}+w_{i t} .
$$

After the fixed effect transformation, equation (5) becomes:

$$
y_{i t}^{*}=\beta_{1}^{i} x_{i t}^{*}+\beta_{i t}^{*} \text {. }
$$

The regression parameter $\beta_{1}$ is estimated by OLS, yielding $\beta_{1}$, residuals $\boldsymbol{\beta}_{i t}$, and sum of squared errors, $S_{0}=\hat{\varepsilon}_{i t} \mathbb{E} \hat{\Theta}_{i t}^{8}$. The likelihood ration test of $H Q$ is based on:

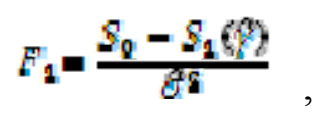

where $S_{0}$ and $S_{1}$ are the residual sum of squared errors obtained from equation (1) without and with threshold effects (or panel threshold estimation), respectively, and $\hat{\sigma}^{2}$ is the residual variance of the panel threshold estimation.

Hansen (1999) recommended the following implementation of the bootstrap for the given panel data. Treat the regressors $x_{i t}$ and threshold variable $q_{i t}$ as given, holding their values fixed in 
repeated bootstrap samples. Take the regression residuals $\varepsilon_{i \tau}^{*}$, and group them by individual,

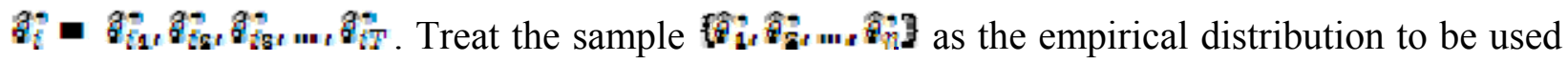
for bootstrapping. Draw (with replacement) a sample of size $n$ from the empirical distribution, and use these errors to create a bootstrap sample under $H Q$.

Using the bootstrap sample, estimate the model under the null hypothesis, equation (6), and alternative hypothesis, equation (4), and calculate the bootstrap value of the likelihood ratio statistic $F_{1}$ (equation (7)). Repeat this procedure a large number of times and calculate the percentage of draws for which the simulated statistic exceeds the actual. This is the bootstrap estimate of the asymptotic p-value for $\mathrm{F}_{1}$ under $H_{0}$. The null hypothesis of no threshold effect will be rejected if the bootstrap estimate of the asymptotic p-value for likelihood ratio statistic $\mathrm{F}_{1}$ is smaller than the desired critical value.

Having established the existence of a threshold effect, $\beta_{\mathbf{1}} \mathbf{\nabla} \beta_{\mathbf{z}}$, it is questionable whether $\hat{\gamma}_{\text {is }}$ consistent for the true value of $Y \quad\left(Y_{1} 0\right)$. This requires the computation of the confidence region around the threshold estimate. While the existence of threshold effect is well accepted, the precise level of the threshold variable is subject to debate. Under normality, the likelihood ratio test statistic, $L R_{n \in \sigma r}=n \frac{S_{n k}(\sigma)-S_{n}(\theta)}{S_{n}(\theta)}$, is commonly used to test for particular parametric values. Hansen (2000) proves that, when the endogenous sample-splitting procedure is used, $E R_{n e s}$ does not have a standard $x^{z}$ distribution. As a result, he suggested that the best way to form confidence intervals for $\gamma$ is to form the "no-rejection region" using the likelihood ratio statistic for a test of $\gamma$. In order to test the null hypothesis $E_{0}: \gamma_{0}$, the likelihood ratio test reject for large values of $\left.L_{1} \gamma_{0}^{\top}\right)$, where

$$
i E_{1}(\gamma)-\frac{S_{1}(\gamma)-S_{1}(\gamma)}{\delta^{2}}
$$

Note that the statistic (equation (8)) is testing a different hypothesis from the statistic (7), that is, $L R_{1}(y)$ is testing $H_{\mathrm{a}}: \gamma_{\mathrm{a}}$ while $\mathrm{F}_{1}$ is testing $H_{\mathrm{a}} \mathrm{i} / \mathcal{R}_{1}=\beta_{\mathrm{a}}$. The likelihood ratio statistic in equation (8) has the critical values, under some technical assumptions, of 5.9395, 7.3523, and 
10.5916 at the significance level $10 \%, 5 \%$ and $1 \%$, respectively. The asymptotic confidence interval for $\gamma$ at a $(1-\alpha)$ confidence level is found by plotting $L R_{\downarrow} \mathbf{J}(\gamma)$ against $\gamma$ and drawing a flat line at the critical level. The null hypothesis will be rejected if the likelihood ratio test statistic exceeds the desired critical value. After the confidence interval for the threshold variable is obtained, the corresponding confidence interval for the slope coefficient can also be easily determined as the slope coefficient and the threshold value are jointly determined, $\beta=\beta(p)$.

In some applications, there may be multiple thresholds. Similar procedures can be extended in a straightforward manner to higher-order threshold models. This method represents another advantage of threshold regression estimation over the traditional approach, which allows for only a single threshold.

The multiple thresholds model may take, for example, the form of the double threshold model:

$$
y_{i t}=\mu_{t}+\beta_{1}^{c} x_{i t} I\left(q_{t t} \leq \gamma_{1}\right)+\beta_{\mathbf{2}}^{c} x_{i t} I\left(\gamma_{\mathbf{1}} \leqslant q_{t t} \leq \gamma_{\mathbf{z}}\right)+\beta_{0}^{c} x_{t t} I\left(\gamma_{\mathbf{z}} \leqslant q_{t t}\right)+e_{i t},
$$

where thresholds are ordered so that $\gamma_{1} \propto \gamma_{2}$. In the panel threshold model, Hansen (2000) also extended a similar computation to multiple thresholds. The general approach is similar to the case of only a single threshold (or the 2 regime case). The method works as follows. In the first stage, let $S_{1}(\gamma)$ be the single threshold sum of squared error of equation (1), and let $\hat{\gamma}_{1}$ be the threshold estimate, which minimizes $\mathfrak{S}_{1}(\%)$. The second stage refers to the estimate of the second threshold parameter, $\hat{F}_{\mathfrak{r}}$, by fixing the first stage estimate, $\hat{\vartheta}_{1}$. The second stage threshold estimate is given by:

$$
\text { frr }=\operatorname{argmin} S_{s}^{r}\left(\mathrm{z}_{\mathrm{s}}\right)
$$

Bai (1997) showed that $\hat{\gamma}^{2}$ is asymptotically efficient, but that $\hat{\gamma}_{1}$ is not, because the estimate $\hat{\gamma}_{1}$ is obtained from a sum of squared errors function which was contaminated by the presence of a neglected regime. The asymptotic efficiency of $F_{2}$ suggests that $\hat{\gamma}_{1}$ can be improved by a third 
stage estimation. Bai (1997) suggests the following refinement estimator. Fixing the second stage estimate, $\hat{P}$, the refined estimate of $\hat{\gamma}_{1}$, that is $\mathscr{1}$, is given by:

$$
\widehat{\gamma}_{1}^{r}=\operatorname{argmtn} S_{1}^{r}\left(\hat{\gamma}_{1}\right)
$$

(11)

This three stage sequential estimation yields the asymptotically efficient estimator of the threshold parameters, $\mathbb{P}$ and $\mathbb{P}$.

In the context of model (9), there is either no threshold, one threshold, or two thresholds. $F_{l}$ in equation (7) is used to test the hypothesis of no threshold against one threshold, and a bootstrapping method is used to approximate the asymptotic p-value. If $F_{l}$ rejects the null of no threshold, a further step based on the model in equation (9) is to discriminate between one and two thresholds.

The minimizing sum of squared errors from the second stage threshold estimate is $\boldsymbol{S}_{2}(\mathrm{~m})$, with a variance estimate, $g^{2}=\frac{S_{2}^{r}(f)}{m(T-1)}$. Thus, an approximate likelihood ratio test of one versus two thresholds can be based on the statistic:

$$
F_{2}-\frac{S_{1}\left(\sigma_{1}\right)-S_{2}^{r}\left(\sigma_{2}\right)}{8^{2}}
$$

where $S_{1}\left(f_{2}\right)$ is the sum of squared errors (SSE) obtained from the first stage threshold

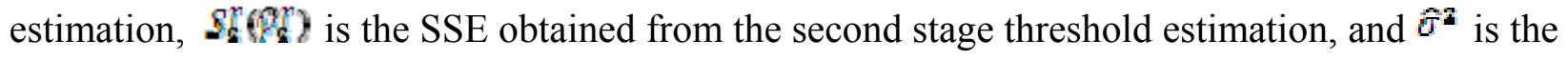
residual variance of the second stage threshold estimation. The hypothesis of one threshold is rejected in favour of two thresholds if $F_{2}$ is large.

Note that the threshold estimators, $\mathbb{P}$ and $\mathscr{P}$, have the same asymptotic distributions as the threshold estimate in a single threshold model. This suggests that we can construct confidence intervals in the same way as described above. 


\subsection{Empirical Specification}

The panel specification of most growth studies can be summarized in the form (see Galimberti 2009)):

$$
y_{t t}-\beta_{1} y_{t, t-1}+\beta_{2} X_{i t}+\beta_{t}+\eta_{t}+\varepsilon_{t t},
$$

where $y_{i}$ is the growth rate, $X_{i c}$ is a vector of explanatory variables, $\mu_{i}$ and $\eta_{c}$ are the country and time specific effects, respectively, $s_{i t}$ is a serially uncorrelated measurement error, and the subscripts $i$ and $t$ refer to country and period, respectively.

From Barro's (1998) growth model, we choose the ratio of real government expenditure in tourism activities to GDP, the ratio of real capital expenditures by direct Travel \& Tourism industry service providers and government agencies to GDP, inflation, and the percentage of gross fixed capital formation as explanatory variables, together with the tourism variable, the growth rate of real Travel \&Tourism GDP to real national GDP. The growth rate of real GDP per capita is the endogenous variable. Specifically, the model takes the form:

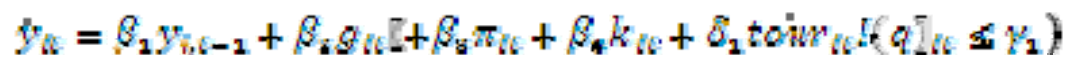

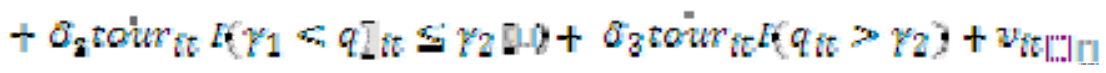

where

$y_{i t}$ is the growth rate of real GDP per capita at time t, $y_{t, t-1}$ is the growth rate of real GDP per capita at time t-1, 
$\Phi_{i t}$ is $\log$ of ratio of real government expenditure in tourism activities to GDP at time $\mathrm{t}$,

$\pi_{i t}$ is inflation at time $\mathrm{t}$,

$k_{\text {it }}$ is $\log$ of the share of capital formation to GDP at time t,

tour $_{t t}$ is the growth rate of real Travel \&Tourism GDP to real national GDP at time t,

$q_{i c}$ is the ratio of real Travel \&Tourism GDP to real national GDP at time t,

$v_{i t}=\mu_{\mathrm{i}}+\eta_{\mathrm{t}}++\varepsilon_{\mathrm{it}}, \mu_{\mathrm{i}}$ is an individual (country) effect, $\eta_{\mathrm{t}}$ is a time effect, and $\varepsilon_{\mathrm{it}}$ is independently and identically distributed across countries and years.

\section{Empirical Results}

The descriptive statistics, namely means, standard deviation, minimum values and maximum values of the variables for the full sample are summarized in Table 3. The results of economic growth and tourism are first examined using a linear specification. This approach allows inclusion of country-specific effects, as well as time-specific effects. Various estimation methods, such as pooled ordinary least squares (pooled OLS), fixed effects (FE), and random effects (RE), are used to estimate the parameters. The regression results are given in Table 4.

\section{[Insert Tables 3 and 4 here]}

According to the benchmark pooled OLS regression, only two variables, namely the growth rate of real GDP per capita in the previous year $\left(y_{i, t-1}\right)$ and $\log$ of share of real government expenditure in tourism activities to GDP $(\mathscr{g r})$, are significant. Furthermore, only the growth rate of real GDP per capita in the previous year is significant, with the expected sign. The estimated coefficient of the growth rate of real Travel \&Tourism GDP to real national GDP ((tewr) $\left.{ }^{2} t t\right)$ is positive, but insignificant. The insignificance of the estimated coefficients is obvious in the case of the inflation rate $\left(\pi_{\omega}\right)$ and the share of capital formation to $\operatorname{GDP}\left(k_{i t}\right)$.

The individual-specific heterogeneity $\mu_{i}$ across countries is to be tested. When the $\mu_{i}$ are correlated with some of the regressors, the fixed effects method is appropriate. The fixed effects model relaxes the assumption that the regression function is constant over time and space. The $\mathrm{F}$ statistic reported in the fixed effects model is a test of the null hypothesis that the constant terms 
are equal across units (the $\mathrm{F}$ statistic that all the $\mu_{i}=0$ is 59.77). A rejection of the null hypothesis indicates that pooled OLS produces inconsistent estimates. The F test following the regression indicates that there are significant individual (country level) effects, implying the fixed effects model is superior to the pooled OLS regression.

All explanatory variables are highly significant in both models, with the growth rate in real Travel \&Tourism economy GDP per capita, and the growth rate in real GDP per capita in the previous year, having positive effects on the growth rate of real GDP per capita. As for the results from pooled OLS, the estimated coefficient of the share of real government expenditure in tourism activities to GDP has a negative effect on the growth rate of real GDP per capita. The estimated coefficients of inflation and gross fixed capital formation have the expected signs. The estimate of rho in both models suggests that almost all the variation in the growth rate in real GDP is related to inter-country differences in the growth rate in real GDP.

We can use a Hausman test to test whether the regressors are correlated with the $\pi_{*}$. The Hausman test results are reported in Table 5, and they do not resoundingly reject the null hypothesis. Thus, the country-level individual effects do not appear to be correlated with the regressors. In summary, the effect of the growth rate in real Travel \&Tourism economy GDP per capita on the growth rate in real GDP per capita is positive and significant across all models. Furthermore, the regression coefficients of government expenditure, inflation, gross fixed capital formation, and real GDP per capita in the previous period are generally consistent with standard results in the economic growth literature.

\section{[Insert Table 5 here]}

\section{Panel Threshold Regression Estimates}

Before applying the threshold regression model, we apply a test for the existence of threshold effect between economic growth and tourism. This paper uses the bootstrap method to approximate the $\mathrm{F}$ statistic, and then calculates the bootstrap p-value. Table 6 presents the empirical results of the test for a single threshold, multiple threshold and triple threshold effects. 
Through 1,200 bootstrap replications for each of the three bootstrap tests, the test statistics $F_{1}, F_{2}$ and $F_{3}$, together with their bootstrap p-values, are also reported. The test statistic for a single threshold is highly significant, with a bootstrap p-value of 0.042 , the test statistic for a double threshold is also significant, with a p-value of 0.054 , but the test statistic for a triple threshold is statistically insignificant, with a p-value of 0.220 . Thus, we may conclude that there is strong evidence that there are two thresholds in the relationship between economic growth and tourism.

Given a double threshold effect between economic growth and tourism, the whole sample is split into 3 regimes, where $q_{i i}$ is used as a threshold variable. Table 7 reports the point estimates of the two thresholds and their asymptotic confidence intervals. These results are useful to see how the threshold variable divides the sample into different regimes.

\section{[Insert Tables 6 and 7 here]}

Figures 5-8 show the threshold estimates from plots of the concentrated likelihood ratio function,

$L R_{1}(\xi)$, corresponding to the first stage estimate of $\hat{\gamma}_{1}$, and $L \mathbb{R}_{2}(\xi)$ and $L \mathbb{R}_{1}(\mathrm{k})$, corresponding to the refined estimators, $\mathscr{P}$ and $\mathscr{P}$, respectively. The $95 \%$ confidence intervals for $\gamma_{2}$ and $\gamma_{1}$ can be found from $L R_{2}(\mathrm{y})$ and $L R R_{1}(\gamma)$ by the values of $\gamma$ for which the likelihood ratio lies beneath the dotted line. In addition, the threshold estimates are the respective values of $\gamma$ at which the likelihood ratio touches the zero axis.

\section{[Insert Figures 5-8 here]}

As mentioned above, where a double threshold is found, a three stage procedure is used to estimate two threshold parameters. The first stage refers to the same estimation procedure as presented for the single threshold model, which yields the first estimate $\hat{\gamma}_{1}$, namely 24.66 . Fixing this threshold parameter, the second stage estimates the second threshold parameter, 8 , which is 14.97. As the estimate $\hat{\gamma}_{3}$ is obtained with neglected regimes, a refinement is needed in this case. The estimate $\hat{\gamma}_{1}$ is improved by a third stage estimation, which yields the refinement estimator of $\hat{\gamma}_{1}$ (or $\mathbb{F}_{1}$ ) of 17.50. The bootstrap p-value obtained from this double threshold 
model is 0.061 . With respect to the threshold estimation results, we do not reject the null hypothesis of a double threshold. As a result, we conclude that there are three regimes in the economic growth and tourism relationship, that is, the observations can be grouped into three regimes for analysis, based on the threshold levels of Git as $14.97 \%$ and $17.50 \%$.

Table 8 shows that the first category indicated by the first point estimates includes countries with a degree of tourism specialization lower than 14.97. The percentage of countries in this group ranges from $80 \%$ to $85 \%$ of the sample over 18 years. The second group is considered as a medium degree of tourism specialization. The countries in this group are not greater than $5 \%$ of the entire sample, and the degree of tourism specialization for this group is relatively tight. A high degree of tourism specialization refers to countries with a degree of tourism specialization in excess of $17.50 \%$. The percentage of countries in this group ranges from $12 \%$ to $16 \%$.

\section{[Insert Table 8 here]}

The estimated model in the empirical framework is as follows:

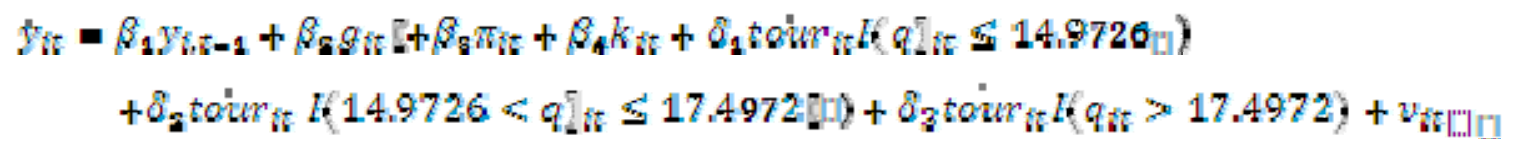

The threshold regression estimates for the economic growth-tourism model, conventional OLS standard errors and White's corrected standard errors for the three regimes are given in Table 9.

\section{[Insert Table 9 here]}

The first conclusion to be drawn is that the effect of government expenditure in tourism activity has the same sign as in the linear specification. The negative and insignificant results for all regimes, and absolute value of the coefficient for government expenditure, were found to be relatively low. This means that the government expenditure associated with travel and tourism, both directly and indirectly linked to individual visitors, such as tourism promotion, aviation, and 
administration, does not have an efficient result in tourism development. Second, the estimated coefficient of inflation is found to be negative and significant. The growth-inflation trade-off is a matter of some controversy. Therefore, the growth-inflation trade-off exists with lower inflation that promotes higher growth, and vice-versa. Third, the share of gross fixed capital formation to GDP, which is a proxy variable for investment in fixed capital assets by enterprises, government and households within the domestic economy, has a positive effect on economic growth.

Focusing on the coefficients of growth rate of real Travel \&Tourism economy GDP per capita, the results for three regimes indicate that there is a significant and positive relationship between the growth rate in real Travel \&Tourism economy GDP per capita and the growth rate in real GDP per capita in regimes 1 and 2, although the effects in both regimes are different. From Table 9, the positive and significant effect of the growth rate in real Travel \&Tourism economy GDP per capita on the growth rate in real GDP per capita in regime 2 is higher, though less significant, than in regime 1 . If $q_{i t}$ is greater than $14.97 \%$ and less than $17.50 \%$, a $1 \%$ increase in the growth rate in real Travel \&Tourism economy GDP per capita may contribute to an increase of $0.2637 \%$ in the growth rate in real GDP per capita, while the same $1 \%$ increase in the growth rate in real Travel \&Tourism economy GDP per capita may account for an increase of only $0.0579 \%$ in the growth rate in real GDP per capita if $q_{i t}$ is not greater than $14.97 \%$ (namely, regime 1).

The evidence presented seems to show that tourism development in most destination economies (accounting for $80-85 \%$ of the sample) does not provide a substantial contribution to economic growth. This is frequently the case in developed and developing countries that are able to build their competitiveness and development on more valued-added industries. It can be observed that there exists no significant relationship between the growth rate in real Travel \&Tourism economy GDP per capita and the growth rate in real GDP per capita in regime 3. In short, when $\mathrm{q}_{\mathrm{it}}$ exceeds $17.50 \%$, tourism growth does not lead to economic growth.

Based on these results, there might be some doubt as to why tourism development could make a significant contribution to GDP as a catalyst for favourable changes in some countries, while others do not have such substantial impacts. The data displayed in Table 10 clarify this issue. 


\section{[Insert Table 10 here]}

It is evident that regime 3 has the highest average percentage of government spending in the tourism sector and percentage of capital investment in tourism activities. This implies that countries in regime 3 tourism development are promoted by, and are supported with, investment in tourism infrastructure and superstructure. Significant levels of capital investment are typically required, so the percentage of capital investment in travel and tourism activities is relatively higher than in the other two regimes. Since a time lag exists between invested inputs and generated output in the form of tourism earnings, the contribution of tourism to the overall economy has not been well recognized. In this case, tourism development during this stage may not contribute to economic growth in the local economies. Furthermore, there is supporting evidence to suggest that many destinations, particularly emerging tourism countries, have attempted to overcome the lack of financial resources to speed up the process of tourism-specific infrastructure development.

With limited opportunities for local public sector funding, these countries have been offered funding by international development organizations or international companies to make themselves more attractive as tourism destinations. Although foreign capital investment can generate extra income and growth from international tourist earnings for the host country, it can generate greater leakages than domestic capital investment from local private and government sources. In addition to the leakages being remitted to the source of international funds, more imported goods may be used to support tourism businesses. As a result, these factors could cause the contribution of tourism to GDP to be less than expected.

On the other hand, countries in regimes 1 and 2 have relatively low government spending and capital investment in the tourism and tourism-related sectors. The countries in these two regimes are possibly developed or developing, and their economies may not be so heavily dependent on the tourism sector. Conversely, they might be able to develop other non-tourism sectors that could make a greater contribution to overall economic growth. Even though we have seen clearly that tourism development in some countries, especially in regime 1, may not have a great impact 
on economic growth, these countries may nevertheless achieve economic growth through their higher valued-added non-tourism sectors.

\section{Concluding Remarks}

Tourism development has significant potential beneficial economic impacts on the overall economy of tourism destinations. This paper has not investigated the direction of the relationship between economic growth and tourism, but whether tourism has the same impact on economic growth in countries that differ in their degree of tourism dependence.

This paper examined a nonlinear relationship between economic growth and tourism by applying the panel threshold regression model of Hansen $(1999,2000)$ to a panel data set of 131 countries over the period 1991-2009. A share of T\&T economy GDP to national GDP was defined as the degree of tourism specialization, and was used as a threshold variable in the model. The main purpose of the paper was to examine whether economic growth was enhanced through tourism development when the sample was split endogenously and, if so, whether such impacts were different across various sub-samples.

The results from threshold estimation identified two endogenous cut-off points, namely $14.97 \%$ and $17.50 \%$. This indicated that the entire sample should be divided into three regimes. The results from panel threshold regression showed that, when the degree of tourism specialization was lower than $14.97 \%$, or was between $14.97 \%$ and $17.50 \%$, there existed a positive and significant relationship between economic growth and tourism. Although such a relationship was found to be significant in both regimes, the magnitudes of those impacts were not the same. It was found that tourism had substantial effects on economic growth in regime 2 , but yielded a slightly lower impact in regime 1 . However, we were unable to find a significant relationship between economic growth and tourism in regime 3, in which the degree of tourism specialization was greater than $17.50 \%$. This could be explained by the fact that there are leakages in those economies where many tourism infrastructure projects have been developed, or where more imported goods are invested in order to support tourism expansion. 
In order to summarize the empirical results, tourism growth does not always lead to economic growth. If the economy is too heavily dependent on the tourism sector, tourism development may not lead to impressive economic growth since the overall contribution of tourism to the economy could be reduced by many factors. It is important to consider the overall balance between international tourism receipts and expenditures, the degree of development of domestic industries, and their ability to meet tourism requirements from domestic production. Should these issues be constantly ignored, then such a country would likely experience lower benefits than might be expected, regardless of whether they are considered to be a country with a high degree of tourism specialization.

\section{References}

Bai, J. (1997), Estimating multiple breaks one at a time, Econometric Theory, 13, 315-352.

Balaguer, J. and M. Cantavella-Jorda (2002), Tourism as a long-run economic growth factor: The Spanish case, Applied Economics, 34, 877-884

Barro, R.J. (1998), Determinants of Economic Growth: A Cross-Country Empirical Study, MIT Press, Edition 1, Volume 1, Number 0262522543, April.

Brau, R., A. Lanza and F. Pigliaru. (2007), How fast are small tourism countries growing? The international 1980-2003 evidence, Milan, Italy, Fondazione Eni Enrico Mattei Nota di Lavoro, No.1.

Brida, J.G., E.J. Sanchez Carrera and W.A. Risso (2008), Tourism's impact on long run Mexican economic growth, Economics Bulletin, 3(21), 1-8.

Dritsakis, N. (2004), Tourism as a long-run economic growth factor: An empirical investigation for Greece using causality analysis, Tourism Economics, 10, 305-316.

Eugenio-Martin, J., N. Morales and R. Scarpa (2003), Tourism and economic growth in Latin American countries: A panel data approach, Tourism and Sustainable Economic Development - Macro and Micro Economic Issues, International Conference, Sardinia, Italy, Fondazione Eni Enrico Mattei Nota di Lavoro, No. 26.

Fayissa, B., C. Nsiah and B. Tadasse (2007), The impact of tourism on economic growth and development in Africa, Working Paper, Department of Economics and Finance, Middle Tennessee State University, Murfreesboro, TN, U.S.A. 
Galimberti, J.K. (2009), Conditioned export-led growth hypothesis: A panel threshold regression approach, MPRA Paper 13417, Available online at http://mpra.ub.unimuenchen.de/13417.

Gunduz, L. and A. Hatemi (2005), Is the tourism-led growth hypothesis valid for Turkey?, Applied Economics, 12, 499-504.

Hansen, B.E. (1999), Threshold effects in non-dynamic panels: Estimation, testing and inference, Journal of Econometrics, 93, 345-368.

Hansen, B.E. (2000), Sample splitting and threshold estimation, Econometrica, 68, 575-603.

Khan, H., S. Phang and R. Toh (1995), The multiplier effect: Singapore's hospitality industry, Cornell Hotel and Restaurant Administration Quarterly, 36, 64-69.

Kim, H.J., Chen, M.H., and Jang, S.C. (2006), Tourism expansion and economic development: The case of Taiwan, Tourism Management, 27, 925-933.

Lee, C.C and Chang, C.P (2008), Tourism development and economic growth: A closer look at panels, Tourism Management, 29, 180-192.

Lee, C. and K. Kwon (1995), Importance of secondary impact of foreign tourism receipts on the South Korean economy, Journal of Travel Research, 34, 50-54.

Lim, C. (1997), Review of international tourism demand models, Annals of Tourism Research, 24, 835-849.

Louca, C. (2006), Income and expenditure in the tourism industry: Time series evidence from Cyprus, Tourism Economics, 12, 603-617.

Oh, C.O. (2005), The contribution of tourism development to economic growth in the Korean economy, Tourism Manangement, 26, 39-44.

Po, W.C and Huang, B.N (2008), Tourism development and economic growth - A nonlinear approach, Physica A: Statistical Mechanics and its Applications, 387(22), 5535-5542.

Sequeira, T.N. and C. Campos (2005), International tourism and economic growth: A panel data approach, Milan, Italy, Fondazione Eni Enrico Mattei Nota di Lavoro, No. 141.

Statistical Yearbook for Asia and the Pacific 2008, United Nations Publications (21 April 2009).

UNWTO World Tourism Barometer (2009), International Tourism Challenged by Deteriorating World Economy, 7(1), January 2009, Available at www.unwto.org.

World Tourism Organization (2008), Tourism and the world economy, in the Facts \& Figures section, available online at http://www.unwto.org/index.php. 
Table 1: Contribution of Tourism towards the Overall Economy GDP and Employment in 2009, and Projection of Travel \& Tourism Economy Real Growth, by Global Regions

\begin{tabular}{|c|c|c|c|c|c|}
\hline Regions & $\begin{array}{c}2009 \text { Travel } \\
\text { \&Tourism } \\
\text { Economy GDP } \\
\text { (US\$ Mn) }\end{array}$ & $\begin{array}{c}2009 \text { Travel } \\
\text { \&Tourism } \\
\text { Economy GDP } \\
\text { \% share }\end{array}$ & $\begin{array}{c}2009 \text { Visitor } \\
\text { Exports } \\
\text { (US\$ Mn) }\end{array}$ & $\begin{array}{c}2009 \text { Travel } \\
\text { \&Tourism } \\
\text { Economy } \\
\text { Employment } \\
\text { (Thous of jobs) }\end{array}$ & $\begin{array}{c}\text { Travel \& } \\
\text { Tourism } \\
\text { Economy Real } \\
\text { Growth } \\
(2010-2019)\end{array}$ \\
\hline Caribbean & $39,410.668$ & 30.312 & $24,154.262$ & $2,042.512$ & 3.568 \\
\hline Central and Eastern Europe & $142,439.966$ & 9.580 & $36,940.472$ & $6,797.150$ & 5.741 \\
\hline European Union & $1,667,656.460$ & 10.716 & $423,685.250$ & $23,003.960$ & 3.808 \\
\hline Latin America & $176,954.984$ & 8.729 & $30,223.315$ & $12,421.720$ & 4.031 \\
\hline Middle East & $158,112.740$ & 11.457 & $50,738.918$ & $5,130.767$ & 4.564 \\
\hline North Africa & $62,893.900$ & 12.164 & $25,622.089$ & $5,440.087$ & 5.417 \\
\hline North America & $1,601,235.000$ & 10.492 & $188,517.700$ & $21,130.230$ & 4.031 \\
\hline Northeast Asia & $1,053,780.332$ & 18.333 & $114,400.124$ & $70,512.123$ & 5.488 \\
\hline Oceania & $115,902.843$ & 18.558 & $38,403.241$ & $1,701.315$ & 4.394 \\
\hline Other Western Europe & $150,082.280$ & 10.207 & $42,694.005$ & $2,277.688$ & 2.642 \\
\hline South Asia & $84,223.460$ & 14.846 & $14,904.677$ & $37,174.593$ & 4.970 \\
\hline South-East Asia & $155,158.492$ & 10.478 & $65,765.366$ & $23,231.522$ & 4.415 \\
\hline Sub-Saharan Africa & $65,866.259$ & 9.047 & $23,392.256$ & $8,948.552$ & 4.718 \\
\hline "World & $=5,473,717.384$ & & $101,079,441.62$ & $219,812.220$ & \\
\hline
\end{tabular}

Source: World Travel and Tourism Council (2009) 
Table 2: Countries in the Sample

\begin{tabular}{|c|c|c|}
\hline \multicolumn{3}{|c|}{ Countries in the sample } \\
\hline Albania & Guinea & Papua New Guinea \\
\hline Algeria & Haiti & Paraguay \\
\hline Angola & Honduras & Peru \\
\hline Antigua and Barbuda & Hong Kong & Philippines \\
\hline Argentina & Hungary & Poland \\
\hline Armania & Iceland & Portugal \\
\hline Australia & India & Qatar \\
\hline Austria & Indonesia & Romania \\
\hline Azerbaijan & Iran & Russia \\
\hline Bahamas & Ireland & Saudi Arabia \\
\hline Bahrain & Israel & Senegal \\
\hline Bangladesh & Italy & Singapore \\
\hline Barbados & Jamaica & Slovakia \\
\hline Belgium & Japan & Slovenia \\
\hline Belize & Jordan & South Africa \\
\hline Benin & Kazakstan & Spain \\
\hline Bolivia & Kenya & Sri Lanka \\
\hline Botswana & Korea Republic & Swaziland \\
\hline Brazil & Kuwait & Sweden \\
\hline Bulgaria & Kyrgyzstan & Switzerland \\
\hline Burkina faso & Laos & Syria \\
\hline Cambodia & Latvia & Tanzania \\
\hline Cameroon & Lebanon & Thailand \\
\hline Canada & Ligya & Tunisia \\
\hline Chile & Lithunia & Turkey \\
\hline China & Luxembourg & Uganda \\
\hline Colombia & Macedonia & U.K. \\
\hline Congo & Madagascar & Ukrain \\
\hline Costa Rica & Malaysia & United Arab Emirates. \\
\hline Croatia & Maldives & U.S.A. \\
\hline Cyprus & Mali & Uruguay \\
\hline Czech Republic & Malta & Venezuela \\
\hline Denmark & Mauritius & Vietnam \\
\hline Dominican Republic & Mexico & Zambia \\
\hline Ecuador & Moldova & \\
\hline Egypt & Morocco & \\
\hline Elsalvador & Mozambique & \\
\hline Estonia & Namibia & \\
\hline Ethiopia & Nepal & \\
\hline Fiji & Netherlands & \\
\hline Finland & New Zealand & \\
\hline France & Nicaragua & \\
\hline Germany & Nigeria & \\
\hline Ghana & Norway & \\
\hline Greece & Oman & \\
\hline Grenada & Pakistan & \\
\hline Guatemala & Panama & \\
\hline
\end{tabular}


Table 3: Summary Statistics

\begin{tabular}{|c|c|c|c|c|c|c|c|}
\hline \multirow{2}{*}{\multicolumn{3}{|c|}{ Variables }} & \multicolumn{5}{|c|}{ Full Sample Summary Statistics } \\
\hline & & & \multirow{2}{*}{$\begin{array}{c}\text { Mean } \\
12.36536\end{array}$} & \multirow{2}{*}{$\begin{array}{l}\text { Std.Dev. } \\
11.64668\end{array}$} & \multirow{2}{*}{$\begin{array}{c}\text { Minimum } \\
1.32169\end{array}$} & \multirow{2}{*}{$\begin{array}{c}\text { Maximum } \\
96.26073\end{array}$} & \multirow{2}{*}{$\begin{array}{l}\text { Observations } \\
\mathrm{N}=2358\end{array}$} \\
\hline ratio of real Travel \&Tourism GDP & $9_{i t}$ & Overall & & & & & \\
\hline \multirow[t]{2}{*}{ to real national GDP } & & Between & & 11.33690 & 2.35479 & 83.32783 & $\mathrm{n}=131$ \\
\hline & & within & & 2.83669 & -5.35055 & 68.52476 & $\mathrm{~T}=18$ \\
\hline \multirow[t]{3}{*}{ growth rate of real GDP per capita } & $\bar{y}_{i t}$ & Overall & 0.840181 & 1.00010 & -0.52356 & 2.42251 & $\mathrm{~N}=2358$ \\
\hline & & Between & & 1.00253 & -0.019801 & 2.35019 & $\mathrm{n}=131$ \\
\hline & & within & & 0.04878 & 0.24956 & 1.37504 & $\mathrm{~T}=18$ \\
\hline \multirow{3}{*}{$\begin{array}{l}\text { growth rate of real GDP per capita } \\
\text { at previous time }\end{array}$} & $y_{6 i}=1$ & Overall & 7.92891 & 1.54701 & 4.63436 & 11.12611 & $\mathrm{~N}=2358$ \\
\hline & & Between & & 1.54323 & 4.84609 & 10.65793 & $\mathrm{n}=131$ \\
\hline & & within & & 0.16987 & 7.15912 & 8.950286 & $\mathrm{~T}=18$ \\
\hline \multirow{3}{*}{$\begin{array}{l}\text { growth rate of real Travel } \\
\text { \&Tourism GDP to real national } \\
\text { GDP }\end{array}$} & $t a m_{f t}$ & Overall & 0.03405 & 0.162411 & -1.36645 & 2.36925 & $\mathrm{~N}=2358$ \\
\hline & & Between & & 0.033051 & -0.02397 & 0.17627 & $\mathrm{n}=131$ \\
\hline & & within & & 0.159037 & -1.30843 & 2.27192 & $\mathrm{~T}=18$ \\
\hline \multirow{6}{*}{$\begin{array}{l}\text { share of real government } \\
\text { expenditure in tourism activities to } \\
\text { GDP }\end{array}$} & $Q_{f t}$ & Overall & 0.79379 & 0.87781 & 0 & 7.70128 & $\mathrm{~N}=2358$ \\
\hline & $P_{t}$ & Between & & 0.84863 & 0.03102 & 5.94578 & $\mathrm{n}=131$ \\
\hline & & within & & 0.23572 & -0.82036 & 4.84453 & $\mathrm{~T}=18$ \\
\hline & $B_{i t}$ & Overall & -0.61925 & 0.87627 & -4.18572 & 2.04139 & $\mathrm{~N}=2358$ \\
\hline & & Between & & 0.84867 & -3.61961 & 1.76885 & $\mathrm{n}=131$ \\
\hline & & within & & 0.22978 & -1.97926 & 2.02238 & $\mathrm{~T}=18$ \\
\hline \multirow[t]{3}{*}{ Inflation rate } & $\pi_{i t}$ & Overall & 1.74439 & 1.37265 & -4.09176 & 8.46272 & $\mathrm{~N}=2358$ \\
\hline & & Between & & 0.95786 & -0.48304 & 5.03489 & $\mathrm{n}=131$ \\
\hline & & within & & 0.98654 & -3.48918 & 7.38377 & $\mathrm{~T}=18$ \\
\hline \multirow{6}{*}{ share of capital formation to GDP } & 霖 & Overall & 22.40727 & 7.71568 & 3.61769 & 210.97330 & $\mathrm{~N}=2358$ \\
\hline & Plt & Between & & 5.05850 & 13.42123 & 46.76865 & $\mathrm{n}=131$ \\
\hline & & within & & 5.84299 & 4.62633 & 206.25890 & $\mathrm{~T}=18$ \\
\hline & $h_{\text {it }}$ & Overall & 3.06672 & 0.28601 & 1.28584 & 5.35173 & $\mathrm{~N}=2358$ \\
\hline & & Between & & 0.20625 & 2.58849 & 3.81526 & $\mathrm{n}=131$ \\
\hline & & within & & 0.19892 & 1.55822 & 5.48806 & $\mathrm{~T}=18$ \\
\hline \multirow[t]{3}{*}{ country } & $i$ & Overall & 66 & 37.82336 & 1 & 131 & $\mathrm{~N}=2358$ \\
\hline & & Between & & 37.96051 & 1 & 131 & $\mathrm{n}=131$ \\
\hline & & within & & 0 & 66 & 66 & $\mathrm{~T}=18$ \\
\hline \multirow[t]{3}{*}{ year } & $t$ & Overall & 1999.5 & 5.189228 & 1991 & 2008 & $\mathrm{~N}=2358$ \\
\hline & & Between & & 0 & 1999.5 & 1999.5 & $\mathrm{n}=131$ \\
\hline & & within & & 5.189228 & 1991 & 2008 & $\mathrm{~T}=18$ \\
\hline
\end{tabular}

Source: Author calculations based on 131 countries for the period 1991 to 2008. 
Table 4: Linear Model Estimates

\begin{tabular}{|c|c|c|c|}
\hline Variable & POLS & Fixed Effect & Random Effect \\
\hline \multirow{2}{*}{$Y_{h i-1}$} & $0.0481 * * *$ & $0.0364 * * *$ & $0.0363 * * *$ \\
\hline & $(3.21)$ & $(6.20)$ & $(6.21)$ \\
\hline \multirow[t]{2}{*}{ twirn } & 0.1510 & $0.0527^{* * *}$ & $0.0527^{* * *}$ \\
\hline & (1.19) & $(8.81)$ & $(8.82)$ \\
\hline \multirow[t]{2}{*}{$g_{\mathrm{t}}$} & $-0.0909 * * *$ & $-0.0154 * * *$ & $-0.0155^{* * *}$ \\
\hline & $(-3.67)$ & $(-3.66)$ & $(-3.70)$ \\
\hline \multirow[t]{2}{*}{$\pi_{i t}$} & 0.0176 & $-0.0088^{* * *}$ & $-0.0088^{* * *}$ \\
\hline & (1.07) & $(-9.10)$ & $(-9.10)$ \\
\hline \multirow[t]{2}{*}{$k_{\text {it }}$} & 0.0433 & $0.0562 * * *$ & $0.0562 * * *$ \\
\hline & $(0.59)$ & $(11.50)$ & $(11.51)$ \\
\hline \multirow[t]{2}{*}{ con_s } & 0.2335 & $0.3830^{* * *}$ & $0.3840^{* * *}$ \\
\hline & $(0.88)$ & (8.38) & $(3.86)$ \\
\hline sigma_u & & 1.00137 & 1.014933 \\
\hline sigma_e & & 0.04584 & 0.04584 \\
\hline rho & & 0.99791 & 0.99796 \\
\hline \multirow[t]{3}{*}{$\mathrm{R}^{2}$} & 0.0087 & within: $\quad 0.1674$ & within: $\quad 0.1674$ \\
\hline & & between: 0.0024 & between: 0.0024 \\
\hline & & overall: 0.0028 & overall: $\quad 0.0028$ \\
\hline Adjusted $\mathrm{R}^{2}$ & 0.0066 & - & - \\
\hline F statistic & 4.14 & 38.68 & - \\
\hline $\mathrm{F}$ test that all $\mathrm{u}_{-} \mathrm{i}=0$ & - & 59.77 & - \\
\hline Wald chi 2 & - & - & 447.82 \\
\hline Prob $>$ F & 0.0010 & 0.0000 & 0.0000 \\
\hline Number of observations & 2358 & 2358 & 2358 \\
\hline Number of groups & - & 131 & 131 \\
\hline $\operatorname{Corr}\left(u \_i, X b\right)$ & - & -0.0098 & 0 (assumed) \\
\hline
\end{tabular}

Note: $* * *, * *, *$ denote significance at the $1 \%, 5 \%$ and $10 \%$ levels, respectively. $\mathrm{t}$-statistics are given in parentheses. 


\section{Table 5: Hausman Test Results}

\begin{tabular}{|c|c|c|c|c|}
\hline \multirow[b]{2}{*}{ Variables } & \multicolumn{2}{|c|}{ Coefficients } & \multirow{2}{*}{$\begin{array}{l}\text { Difference } \\
\text { (b-B) }\end{array}$} & \multirow{2}{*}{$\begin{array}{c}\text { sqrt (diag(V_b-V_B }) \\
\text { S.E. }\end{array}$} \\
\hline & $\mathrm{Fe}(\mathrm{b})$ & $\operatorname{Re}(\mathrm{B})$ & & \\
\hline$y_{t, t-1}$ & .0364215 & .036288 & .0001335 & .0006424 \\
\hline towr & .0527214 & .0527437 & -.0000223 & .0002325 \\
\hline$g_{t t}$ & -.0154018 & -.0155513 & .0001494 & .0002607 \\
\hline$\pi_{t \varepsilon}$ & -.0088247 & -.0088206 & $-4.14 \mathrm{e}-06$ & .0000394 \\
\hline$k_{i t}$ & .0562243 & .0562201 & $4.18 \mathrm{e}-06$ & .0002186 \\
\hline
\end{tabular}




\section{Table 6: Test for Threshold Effects}

\begin{tabular}{cccc}
\hline Test & F statistics & Bootstrap p-value & $\begin{array}{c}\text { Critical values } \\
(10 \%, 5 \%, 1 \% \text { critical values })\end{array}$ \\
\hline Single Threshold & 20.4055 & $0.0420^{* *}$ & $(13.4295,17.9914,31.5974)$ \\
Double Threshold & 20.1857 & $0.0540^{*}$ & $(16.2184,20.5159,101.1189)$ \\
Triple Threshold & 8.4478 & 0.2200 & $(14.0185,22.3348,38.9682)$ \\
\hline
\end{tabular}

$* *, *$ denote significance at the $5 \%$ and $10 \%$ levels, respectively. 


\section{Table 7: Threshold Estimates}

\begin{tabular}{|c|c|c|c|}
\hline Test & Threshold estimate & Confidence region & Sum of Squared Errors \\
\hline Single Threshold & 24.6586 & {$[18.2679,26.6774]$} & 3.9006 \\
\hline Double Threshold & & & \\
\hline First iteration: & 14.9726 & {$[13.8469,15.5572]$} & 3.8656 \\
\hline Fixed threshold 24.6586 & Thresholds: 14.972624 .6586 & & \\
\hline Second iteration: & 17.4972 & {$[16.4665,24.6586]$} & 3.8553 \\
\hline Fixed threshold 14.9726 & Thresholds: 14.972617 .4972 & & \\
\hline Triple Threshold & & & \\
\hline Fixed thresholds: & 24.6586 & {$[6.4159,69.3503]$} & 3.8407 \\
\hline 14.972617 .4972 & Thresholds: 14.972617 .497224 .6586 & & \\
\hline
\end{tabular}


Table 8: Percentage of Countries in the Three Regimes Across Years

\begin{tabular}{|c|c|c|c|c|c|c|c|c|c|c|c|c|c|c|c|c|c|c|}
\hline \multirow{2}{*}{ Regime } & \multicolumn{18}{|c|}{ Year } \\
\hline & 1991 & 1992 & 1993 & 1994 & 1995 & 1996 & 1997 & 1998 & 1999 & 2000 & 2001 & 2002 & 2003 & 2004 & 2005 & 2006 & 2007 & 2008 \\
\hline fit fis 14A7g6 & 83 & 85 & 81 & 83 & 85 & 82 & 83 & 83 & 85 & 82 & 82 & 80 & 82 & 80 & 83 & 79 & 79 & 80 \\
\hline 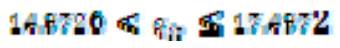 & 5 & 2 & 4 & 1 & 1 & 5 & 3 & 2 & 1 & 3 & 4 & 4 & 4 & 5 & 0 & 5 & 5 & 4 \\
\hline 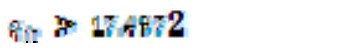 & 12 & 13 & 15 & 16 & 15 & 13 & 14 & 15 & 15 & 15 & 14 & 16 & 15 & 15 & 17 & 16 & 16 & 16 \\
\hline Total & 100 & 100 & 100 & 100 & 100 & 100 & 100 & 100 & 100 & 100 & 100 & 100 & 100 & 100 & 100 & 100 & 100 & 100 \\
\hline
\end{tabular}


Table 9: Endogenous Threshold Regression for Double Threshold Model

\begin{tabular}{|c|c|c|c|}
\hline Regressors & Coefficient Estimates & OLS S.E. & White S.E \\
\hline$y_{t, t-1}$ & $\begin{array}{l}0.0233^{* * *} \\
(2.787)\end{array}$ & 0.0061 & 0.0084 \\
\hline $8 t$ & $\begin{array}{l}-0.0109^{*} \\
(-1.849)\end{array}$ & 0.0043 & 0.0059 \\
\hline$m_{i s}$ & $\begin{array}{l}-0.0103 * * * \\
(8.0078)\end{array}$ & 0.0009 & 0.0013 \\
\hline$k_{i t}$ & $\begin{array}{l}0.0535^{* * *} \\
(7.1004)\end{array}$ & 0.0049 & 0.0075 \\
\hline 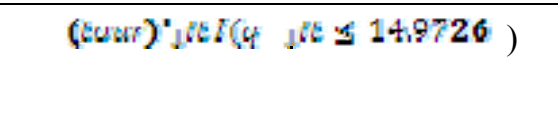 & $\begin{array}{l}0.0579 * * * \\
(5.6876)\end{array}$ & 0.0064 & 0.0102 \\
\hline 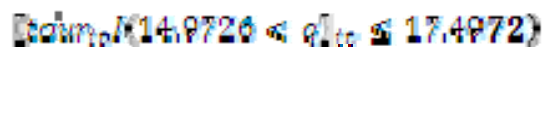 & $\begin{array}{l}0.2637 * * * \\
(2.9763)\end{array}$ & 0.0359 & 0.0886 \\
\hline to $u r^{\prime} I t\left(q_{i t}=17,4872\right)$ & $\begin{array}{c}0.0027 \\
(0.0780)\end{array}$ & 0.0168 & 0.0343 \\
\hline
\end{tabular}

Note $* * *, * * *$ indicate significance at the $1 \%, 5 \%$ and $10 \%$ levels, respectively. t-statistics are given in parentheses. 
Table 10: Average share of real T\&T Economy GDP, Government Expenditure in $T \& T$, and Capital Investment in $T \& T$ in the Three Regimes

\begin{tabular}{|c|c|c|c|}
\hline Regime & $\begin{array}{c}\text { Share of real T\&T economy GDP } \\
\text { to national GDP }(\%)\end{array}$ & $\begin{array}{c}\text { Government expenditure in T\&T } \\
\text { activities }(\%)\end{array}$ & $\begin{array}{c}\text { Capital investment in T\&T } \\
\text { activities (\%) }\end{array}$ \\
\hline \multicolumn{4}{|l|}{ Regime 1} \\
\hline 1991 & 7.4068 & 0.5047 & 2.1203 \\
\hline 1992 & 7.8389 & 0.5294 & 2.3278 \\
\hline 1993 & 7.9017 & 0.5185 & 2.1725 \\
\hline 1994 & 8.0327 & 0.5443 & 2.1576 \\
\hline 1995 & 8.2525 & 0.5280 & 2.2226 \\
\hline 1996 & 8.3262 & 0.5129 & 2.2174 \\
\hline 1997 & 8.3912 & 0.5139 & 2.2677 \\
\hline 1998 & 8.5691 & 0.4965 & 2.3603 \\
\hline 1999 & 8.8774 & 0.5133 & 2.3181 \\
\hline 2000 & 8.8029 & 0.5074 & 2.2175 \\
\hline 2001 & 8.9258 & 0.5339 & 2.2024 \\
\hline 2002 & 8.7334 & 0.5119 & 2.2274 \\
\hline 2003 & 8.7633 & 0.5202 & 2.1965 \\
\hline 2004 & 8.6424 & 0.5150 & 2.1942 \\
\hline 2005 & 8.9432 & 0.5143 & 2.2772 \\
\hline 2006 & 8.6445 & 0.4993 & 2.2640 \\
\hline 2007 & 8.5787 & 0.4864 & 2.3082 \\
\hline 2008 & 8.5157 & 0.4833 & 2.2490 \\
\hline average & 8.4526 & 0.51299 & 2.23896 \\
\hline \multicolumn{4}{|l|}{ Regime 2} \\
\hline 1991 & 16.6349 & 1.0807 & 3.9583 \\
\hline 1992 & 16.6349 & 1.0807 & 3.9583 \\
\hline 1993 & 16.4542 & 1.6503 & 4.8336 \\
\hline 1994 & 16.3098 & 0.9885 & 5.1155 \\
\hline 1995 & 16.4665 & 1.2148 & 4.1081 \\
\hline 1996 & 16.5037 & 1.1253 & 5.2113 \\
\hline 1997 & 16.4629 & 1.0479 & 5.0210 \\
\hline 1998 & 16.4712 & 1.1764 & 3.8771 \\
\hline 1999 & 15.7195 & 1.2163 & 3.5854 \\
\hline 2000 & 16.1261 & 1.6043 & 3.5029 \\
\hline 2001 & 16.0737 & 1.1242 & 3.8655 \\
\hline 2002 & 16.2984 & 1.2753 & 4.4813 \\
\hline 2003 & 15.9190 & 1.5520 & 4.5139 \\
\hline 2004 & 15.8353 & 0.7495 & 4.1083 \\
\hline 2005 & - & - & - \\
\hline 2006 & 15.7999 & 0.7249 & 3.0856 \\
\hline 2007 & 15.9831 & 0.8390 & 3.2117 \\
\hline 2008 & 16.6521 & 0.9503 & 5.4546 \\
\hline average & 16.2556 & 1.141239 & 4.22900 \\
\hline \multicolumn{4}{|l|}{ Regime 3} \\
\hline 1991 & 35.0274 & 2.5356 & 8.3858 \\
\hline 1992 & 34.1860 & 2.4402 & 8.2951 \\
\hline 1993 & 32.1864 & 2.3555 & 8.0852 \\
\hline 1994 & 31.3978 & 2.3831 & 8.3702 \\
\hline 1995 & 30.8079 & 2.3361 & 8.0110 \\
\hline 1996 & 32.8733 & 2.2550 & 7.7172 \\
\hline 1997 & 32.9462 & 2.2600 & 7.7512 \\
\hline 1998 & 31.9584 & 2.3144 & 7.8555 \\
\hline 1999 & 31.8463 & 2.2663 & 7.4633 \\
\hline 2000 & 32.2201 & 2.0916 & 7.4033 \\
\hline 2001 & 32.8163 & 2.2172 & 7.6275 \\
\hline 2002 & 32.4652 & 2.2841 & 7.4957 \\
\hline 2003 & 35.2794 & 2.1983 & 8.0589 \\
\hline 2004 & 34.1546 & 2.1811 & 7.4892 \\
\hline 2005 & 29.9342 & 1.9120 & 7.2290 \\
\hline 2006 & 33.9788 & 2.0128 & 9.2495 \\
\hline 2007 & 33.9435 & 2.0217 & 9.1027 \\
\hline 2008 & 35.3307 & 2.1873 & 8.7882 \\
\hline
\end{tabular}




\section{Figure 1: World Inbound International Tourist Arrivals}

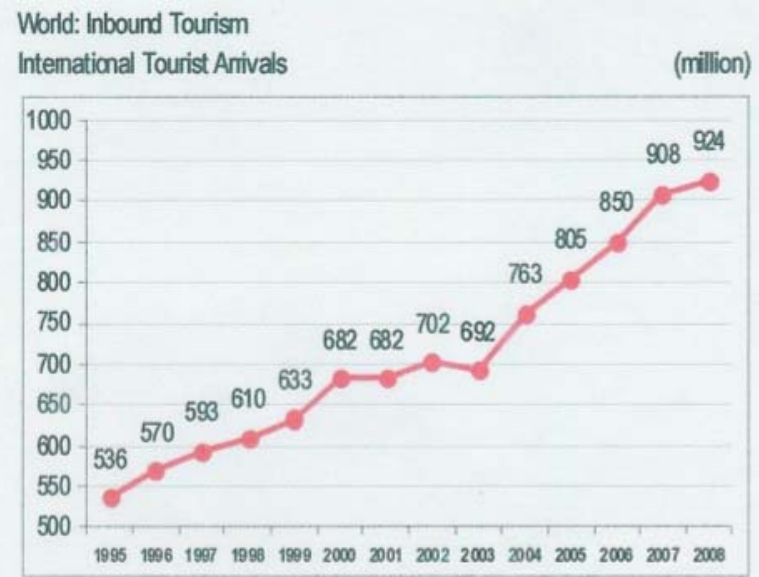

Source: World Tourism Organization 
Figure 2: Shares in International Tourist Arrivals, Global Regions, 1990 to 2006

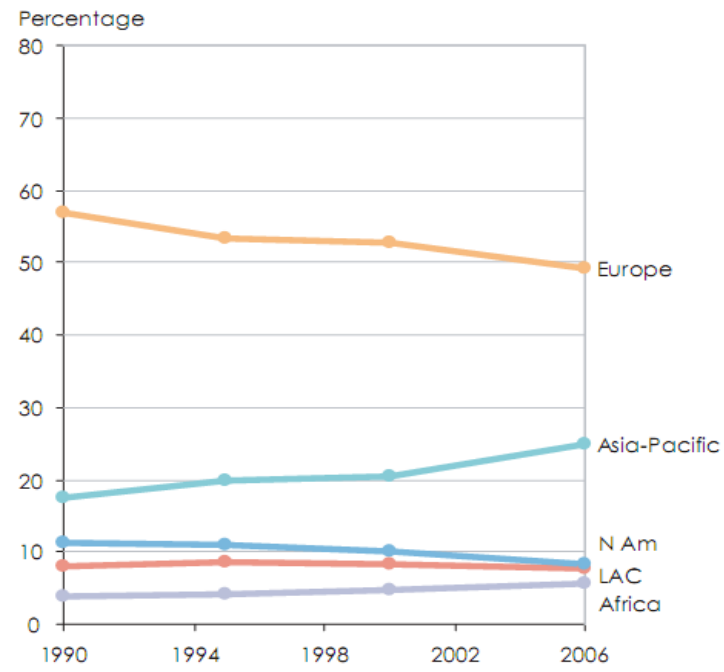

Source: Statistical Yearbook for Asia and the Pacific 2008 
Figure 3: Market Shares in International Tourism

Receipts, by Global Region, 1990 to 2006

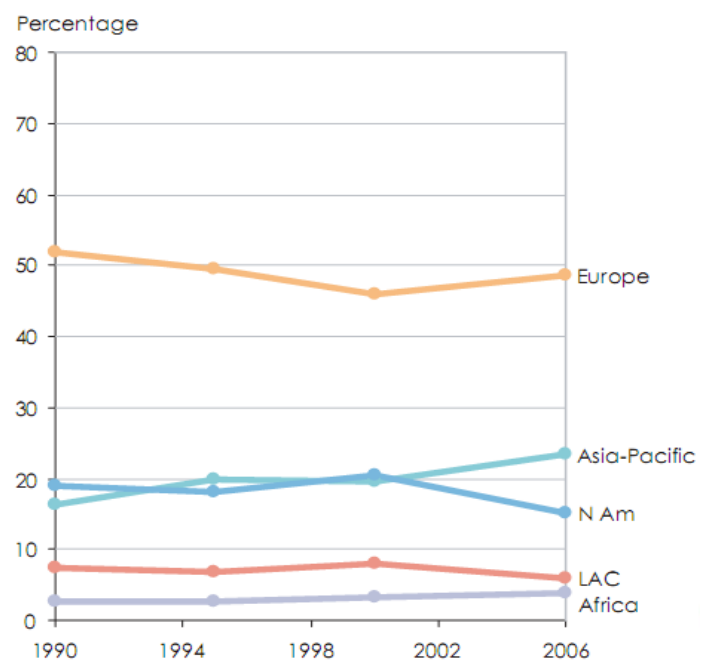

Source: Statistical Yearbook for Asia and the Pacific 2008 
Figure 4: Economic Growth and International Tourist Arrivals, 1975-2005

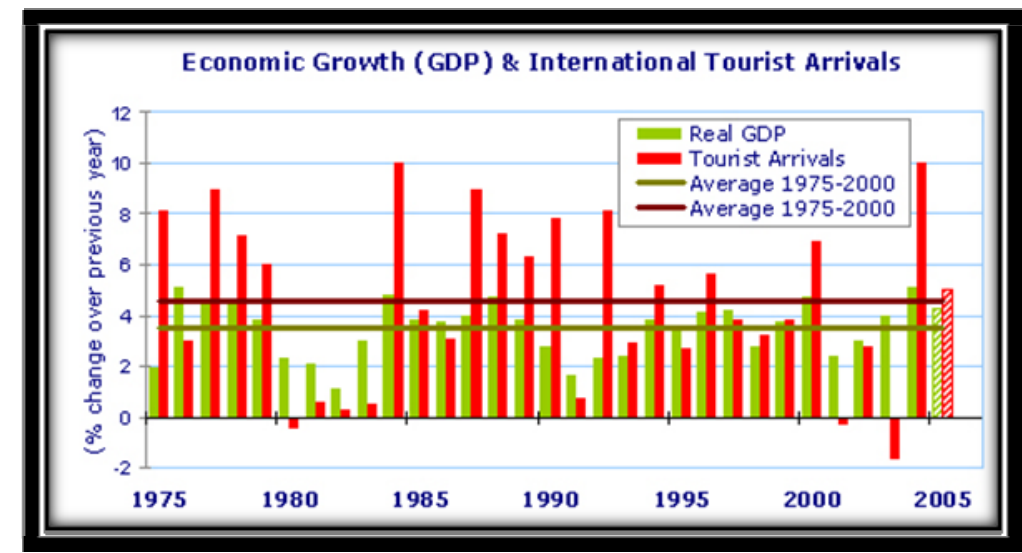

Source: World Tourism Organization; International Monetary Fund 
Figure 5: Confidence Interval Construction for Single Threshold

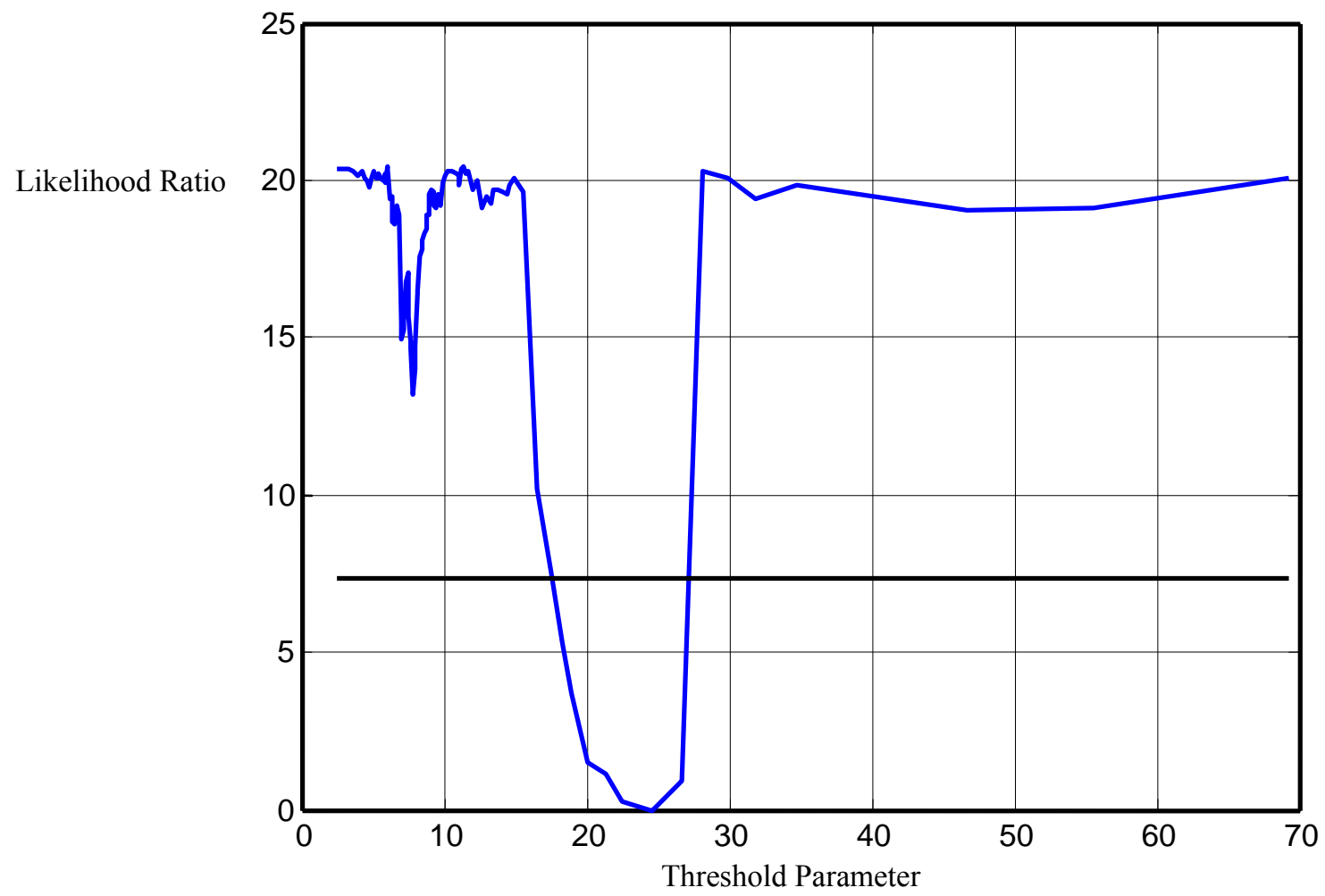


Figure 6: Confidence Interval Construction for Double Threshold

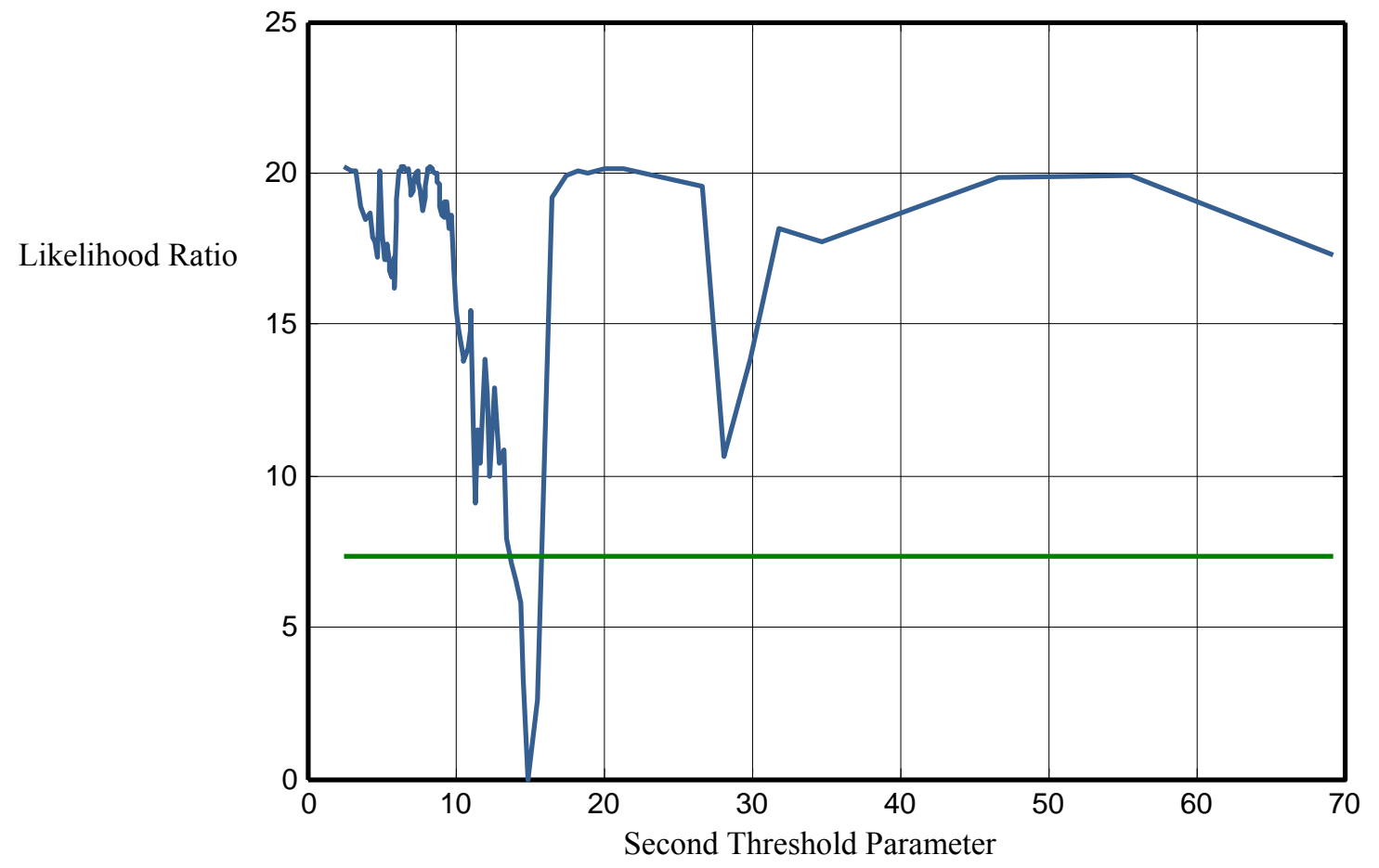


Figure 7: Confidence Interval Construction for Double Threshold

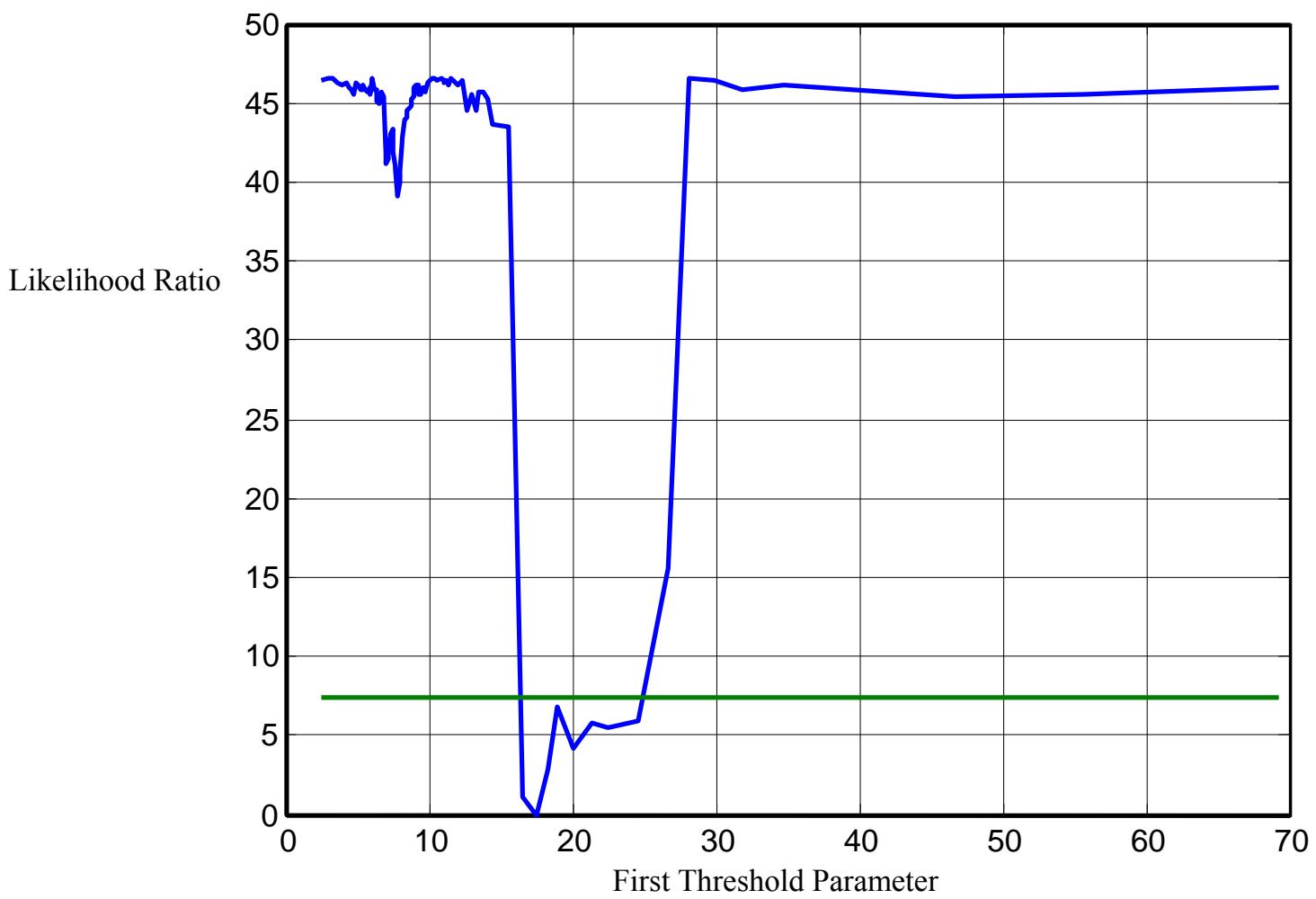


Figure 8: Confidence Interval Construction for Triple Threshold

Likelihood Ratio

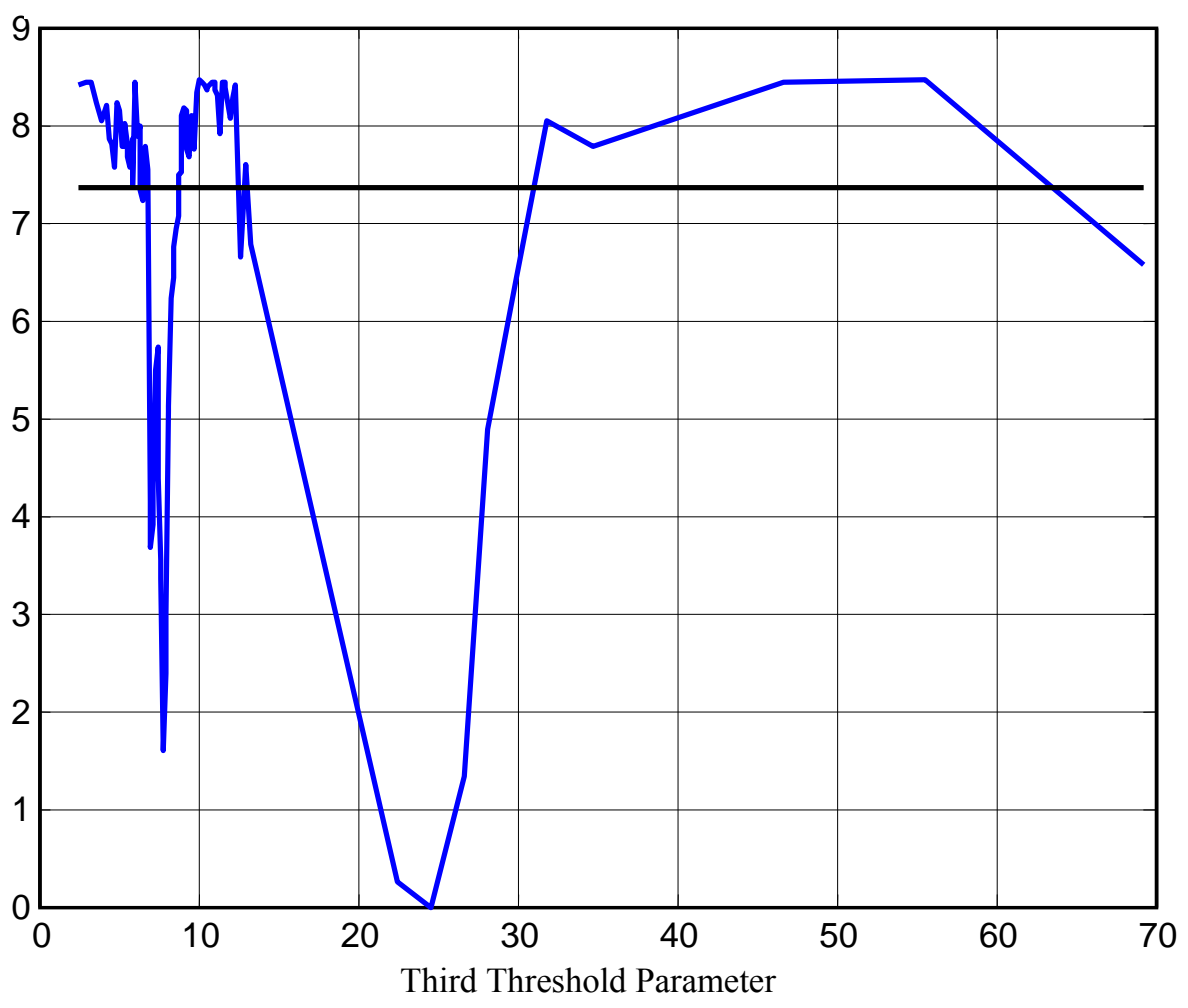

